deliberately takes the widest possible meaning and hence leads from the general concept of the ocumene, or habitable part of the earth's surface, through the varied types of rural habitat, to the growth of towns and the great cities considered as environments wherein human beirgs pass their lives.

The field is vast in both space and time, and the bibliographies attached to each of the thirteen chapters show how widely the scattered literature has been studied, especially that of France, Germany, Britain, the United States and Italy. The bibliographies alone would render this work indispensable to the serious student of human geography, but the care with which the author has sought his material is matched by the care with which he has set out his findings. A laudable feature is the separation-in the case of the rural habitat into two separate chapters-of facts and theories. While much of the material on towns lies perhaps in the general field of sociology, an interesting chapter is devoted to large towns as a human milieu in which features of the local and micro-climates are examined. In another chapter the functions of a town are considered under three headings-social (listed as military, spiritual and political), exchange or commercial, and industrial. Among the difficult questions which inevitably arise are the definition of a town and the contrast with an overgrown village, the problem which has so much exercised town planners in recent years-the definition and delimitation of urban hinterland or Umland.

In the general conclusion to the whole work, which occupies the last forty-five pages of this volume, Sorre takes up briefly the vexed question of the natural region and its definition, and so leads to those areas of the earth's surface which have cradled the great civilizations of the past as well as of more recent times. He proceeds finally to the distribution of man on the habitable earth, noting the present-day development of power as a great localizing factor. The growing pressure of population on space he leaves, presumably, for his successors to worry about.

One would have liked more text-figures, since the thirty-two given, though appropriate enough, are all from familiar sources. So much scholarship deserves a better index : no authors are listed in the six pages devoted mainly to indexing places. On the other hand, a useful subject analysis to the four volumes is included. Proof-reading, especially of foreign authors' names and titles of books and papers, leaves something to be desired; but these are minor blemishes in a work of great value.

L. Dudley Stamp

\section{MOLECULAR ARCHITECTURE}

\section{Die Struktur des freien Moleküls}

Allgemeine physikalische Methoden zur Bestimmung der Struktur von Molekülen und ihre wichtigsten Ergebnisse. Von Prof. H. A. Stuart. (Die Physik der Hochpolymeren, Band 1.) Pp. xxi+609. (Berlin, Göttingen und Heidelberg: Springer-Verla.g, 1952.) 69 D. marks.

THIS is one of a series of four volumes by different authors designed to describe the physical architecture and properties of high polymers. But since polymers are built up out of smaller units, it is natural that the first volume should be concerned with the structure of a free molecule of not more than twenty or thirty atoms, and with the type of experiment which can be made to provide information about this structure.

Let it be said at once : this is a massive effort. The six hundred pages are literally packed with tables of numerical values, varying from interatomic distances and force constants for vibration to polarizability tensors and Kerr constants. Few people can boast such a wide experience in the physical behaviour of molecules as H. A. Stuart, now professor of physics at Hannover. It has been his intention to include between the two covers of this one volume every known approach to the study of molecular structure. The result of his efforts is something unlike any other account at present available. It will inevitably become a standard reference work for a good many years to come.

One is tempted to compare the present book with the well-known accounts by Prof. G. Herzberg, since these are the only comparable discussions of molecular structure on anything like the same scale. There is much less overlapping than one might have thought. This happy situation results from the different approaches of the two authors. Herzberg is interested in the internal structure of a molecule, and he is always asking: Why is this as it actually is ? Stuart is chiefly concerned with discovering what the properties are, and with systematizing them, but without any desire to 'explain' them. If all reference to wave mechanics were removed, Herzberg's books would be mauled almost beyond acceptance; Stuart's book would scarcely be affected. For Schrödinger's name does not even appear in the author index, nor can wave mechanics be found in the subject index. The wave equation itself appears merely in a footnote, and then only in relation to the description of a highly simplified molecular system. Herzberg gives elaborate descriptions of molecular states; Stuart covers the electron classification in molecules in a couple of pages, and dismisses resonance in about the same space. But, for tables of dipole moments, the latest microwave results for bondlengths, the polarizabilities of molecules and of bonds, depolarization factors, molecular association and intermolecular forces, the reader will look to Stuart and not be disappointed. The literature is exceedingly well covered, up to about 1950: when one realizes the extremely wide variety of fields under review, this is a quite remarkable achievement. Perhaps I was unlucky; but $\mathrm{I}$ found no less than five minor mistakes in the references in about half an hour's test.

As might be expected from such an author, there is a great deal of emphasis on the sizes of atoms and ions; and a great deal of information about the scattering of light by small, and large, molecules which is not easily found elsewhere. There are certain notable omissions, such as to the work of Ingold on the structure of benzene, and to the famous JahnTeller theorem on the stability of molecules with degenerate energy-levels. In one or two places, such as the ultra-violet absorption of polyenes and the free-electron model, the account seems to me rather inadequate; in one or two others, such as the old and larger value for the dissociation energy of $\mathbf{F}_{2}$, it is a little out of date. But these are all relatively minor blemishes in a book which admirebly serves its purpose of describing particularly those physical aspects of molecular structure which are relevant to the subsequent study of high polymers.

C. A. Covison 